\title{
Chapter 24 \\ Managing Life Cycle Sustainability Aspects in the Automotive Industry
}

\author{
Marzia Traverso, Patrick Kim, Stefan Brattig, and Volkmar Wagner
}

\begin{abstract}
An important target on the way to a sustainable development is ensuring a more sustainable production and a reduced consumption of energy and material resources. The automotive industry is considered one of the most strategic contributors to reach this objective. On the one hand, the automotive sector represents a meaningful pillar for the economic stability and social welfare of several countries; on the other hand, with its huge supply chain, it is often a cause of negative environmental as well as social impacts. In the past, the main focus was the reduction of environmental impacts in the use phase first, and then along the entire life cycle. More recently, the attention has moved to include the social performance according to the three pillars concept of sustainability. If the target of achieving a more sustainable development is clear, the methodology and tools that should be used to assess the sustainability performance of a vehicle along its life cycle still needs to be settled. This chapter presents and discusses the benefits and challenges of methods and tools that have been used in the automotive industry.
\end{abstract}

Keywords Life cycle assessment $\bullet$ Life cycle costing • Life cycle management - Life cycle sustainability assessment - Social hotspot database - Social life cycle assessment $\bullet$ Social sustainability $\bullet$ Sustainability $\bullet$ UNEP/SETAC life cycle initiative

\section{Introduction}

Since the publication of the Brundtland report (WCED 1987), a new concept of economic development has been defined. According to it, a real long-term economic growth cannot be achieved without the insurance of social equality and environmental protection. An overview of intervention areas towards sustainable development were identified and reported by United Nations Secretary-General's High-level Panel on Global Sustainability in the report 'Resilient People, Resilient Planet: A

M. Traverso $(\bowtie) \bullet$ P. Kim $\bullet$ S. Brattig $\bullet$ V. Wagner

Product Sustainability, BMW Group, Knorrstraße 147, 80788 Munich, Germany

e-mail: marzia.traverso@bmw.de 
future worth choosing' (UN 2012). The Panel's list of sustainability actions to be implemented consists of: eradicating poverty; reducing inequality and making growth inclusive; making production and consumption more sustainable, combating climate change and respecting a range of other planetary boundaries; enabling consumers to make sustainable choices and to advance responsible behaviour individually and collectively; managing resources and enabling a twenty-first century green revolution in the fields of agriculture, energy and technology. Among these challenges, the automotive industry can play a meaningful role along its whole supply chain in the achievement of more sustainable production and consumption. In the past, the main focus was placed on the environmental performance of the vehicle with particular attention to the use phase. In recent years, thanks to the media and non-governmental organizations, the interest in the social and working conditions of employees and the social impact on the local communities has been increasing.

According to several scientific references the assessment of sustainability performance of a product can be obtained with the life cycle sustainability assessment (LCSA) as defined in (Finkbeiner et al. 2010; Klöpffer 2008; UNEP/SETAC 2012):

$$
\mathrm{LCSA}=\mathrm{LCA}+\mathrm{LCC}+\mathrm{SLCA}
$$

This formal equation means that to assess the sustainability performance of the product, we need to consider jointly the life cycle assessment (LCA) (ISO 2006), the life cycle costing (LCC) (Schmidt 2003) and the social life cycle assessment (SLCA) (UNEP/SETAC 2009) within the same or equivalent system boundary and related to the same functional unit of the considered product.

If the formal definition of this method has found the agreement of the scientific community, its implementation still presents a lot of challenges. These challenges are particularly significant in the automotive sector where the product has a long and complex life cycle and most of the experience has been matured for the assessment of the environmental performances.

If we are looking at the life cycle of a conventional vehicle and its relative environmental impacts, the use phase still constitutes the major portion (Fig. 24.1). It plays a meaningful role in the energy consumption and it has a direct economic impact on the customer. With the past increase of crude oil prices, and the introduction of emission limits for the vehicles, the interest for less consuming and more efficient cars has led most automotive companies to reduce the cars' weight by choosing lighter materials and to improve their efficiency in the use phase.

An example of a strategy to reach this target is the Efficient Dynamics strategy developed and adopted by BMW Group. This includes improving the aerodynamics of the vehicles, choosing lighter materials for reducing the tailpipe emissions and fuel consumption, and introducing functions such as auto start/stop, air vent control and brake energy regeneration (BMW Group 2010). Focusing the attention only on the use phase has resulted in the reduction of the environmental impact this step of the life cycle, but it does not necessarily improve the overall environmental performance of the car. Indeed, when we introduce more light-materials, components 


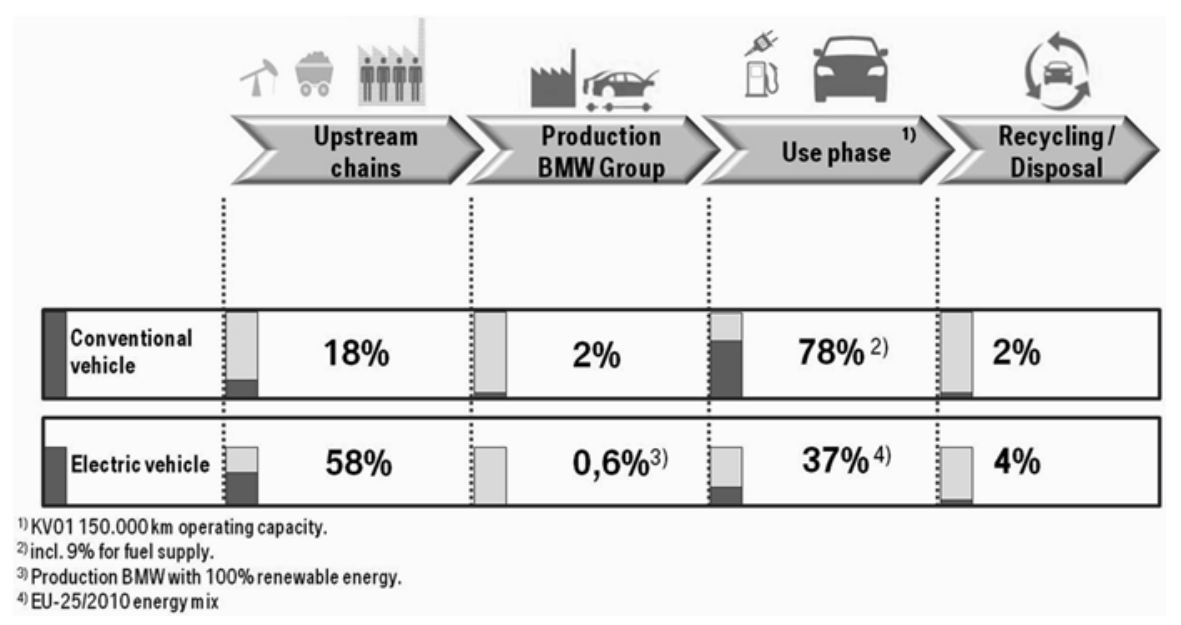

Fig. 24.1 Global warming potential $\left[\mathrm{CO}_{2} \mathrm{e}\right]$ results along the vehicle life cycle at BMW Group

we often move the environmental impact from the use phase to the manufacturing one. That is the main reason why BMW Group develops its vehicles based on a life cycle philosophy.

If we consider a more comprehensive sustainability performance of a product then the focus on only the environmental impacts, or even more so on just one environmental impact category, e.g. global warming potential (GWP) (IPCC 2001) is not enough. Focusing the attention only on the reduction of $\mathrm{CO}_{2} \mathrm{e}$ leads to the usage of more renewable raw materials in a product, but this can cause a negative impact on biodiversity as well as generate competition with the food sector in developing countries if not managed properly. Moreover, the agriculture sector is considered a compartment with high social risks; in fact working conditions, wages, and human rights are often social issues of this sector and must be evaluated.

A picture of the available and currently used techniques to assess environmental, economic and social sustainability performances of a product are presented in this chapter with their benefits and limits.

\section{Assessing Sustainability Performance Within a Vehicle Life Cycle}

\subsection{Life Cycle Assessment of a Car}

Life cycle assessment (LCA) is recognized as a scientifically valid method for assessing the environmental performance of a product and it is the only life cycle technique which has been standardized so far (ISO 2006b: ISO 14040). 
The LCA according to the ISO 14040/44 (ISO 2006a: ISO 14040, ISO 2006b: ISO 14044) is currently used at BMW Group as a supporting decision-making tool in the development process of the car to orient designers and engineers towards developing a car with a better environmental performance. The LCA is also used as monitoring tool to check the product concept and its relative environmental impacts in each phase of the development process.

Reduction targets for each environmental impact category can be established according to the company and national strategy, and the relative improvements of a car compared with its previous model can consequently be assessed and confirmed. The main focus of the automotive sector is still on global warming potential (GWP) (IPCC 2001) for the reduction of greenhouse gases along the entire life cycle of the vehicle, but the other impact categories are monitored as well. Realizing a car with a better LCA balance than its previous model is only possible by acting on the use phase as well as in the manufacturing one. Examples of measures used at BMW Group to reach a higher environmental performance are: use of more secondary source of materials such as metals and thermoplastics, promotion of less energyintensive materials, components produced with renewable energy sources, and improvement of the recyclability of the car's components at the end of life (EoL).

According to the ISO 14040/44 (2006) you can carry out an LCA on a car and obtain different results. This happens because the ISO 14040 and ISO 14044 (ISO 2006a: ISO 14040, ISO 2006b: ISO 14044) leave a lot of freedom and flexibility in the implementation of the method; several parameters, such as system boundaries, allocation criteria, data sources and database used can be established differently case by case and can strongly affect the results. The important element for making the LCA study valid is its transparency and the reproducibility of its implementation. Most LCA studies at BMW Group are used to support internal decision-making processes and they contain confidential information that cannot be easily published. In order to conform to the ISO 14044 regarding the reproducibility of the implementation, and to be able to use part of the LCA results in the company's communication, it is necessary to ensure that the entire process, the data, the results and the related communication material are validated and proofed by a third party certification office. This procedure is commonly used in the German automotive sector, and the proliferation of different "certificates" has increased in the last few years. BMW Group reports its LCA results in the Sustainability Value Report (BMW Group 2013), and with the Environmental Certification validated by TÜV SÜD (BMW Group 2014).

Considering this, what are the further levers to improve the environmental performance of a vehicle?

If it is true that a reasonable improvement has been reached and is still ongoing in the use phase, it is also true that more efforts have to be made to improve it by considering the manufacturing phase. The manufacturing phase of a car includes all phases from extraction of raw materials throughout the components' production to the assembly and manufacture of the car itself. The last part is normally directly under the control of the OEM (Original Equipment Manufacturer), whereas the rest is carried out by the upstream supply chain. The necessity to find new levers and 
new potentials in the supply chain has led to a push towards a more direct cooperation with our suppliers for a more sustainable production. This is clearly a big challenge in the automotive sector where the supply chain is long and complex and involves a large number of actors. The approach used in this case can be very different company to company and from car to car. A proliferation of activities in sectors strongly related with the automotive industry has started to improve the environmental and/ or sustainability performances and to harmonize the methodologies used. An example of these initiatives is the Aluminium Stewardship Initiative.

The Aluminium Stewardship Initiative (ASI) was launched in 2012 to foster greater sustainability and transparency throughout the aluminium industry. It involves several key industry players in the aluminium supply chain such as BMW Group, Rio Tinto, Novelis, to name just a few (Aluminium Stewardship Initiative 2014). The main target of this initiative is to develop an Aluminium Stewardship Initiative Standard to address the environmental, social and governance aspects of the aluminium value chain. The ASI aims, by mobilising a broad base of stakeholders, to establish and promote responsible environmental, social and governance practices across the aluminium value chain. Throughout this standard it will be possible to further support the closed-loop recycling process in the aluminium production system and the inventory data retrieval for a transparent LCA.

At BMW, the LCA is also often used as an assessment method to compare different mobility concepts: conventional and electro-mobility, public transportation, car sharing. It is used to understand the potential impact of the development of one of these concepts on a large scale or to compare concepts among one another towards a more sustainable choice.

\subsection{Social and Economic Performances}

According to the definition of sustainability, economic and social factors should also be considered to establish the comprehensive sustainability performance of a product.

The economic performance in terms of the business case of a project/product is always considered, but it does not necessarily follow the framework introduced by the LCC (Swarr et al. 2011). LCC is defined as a compilation and assessment of all costs related to a product for a specific stakeholder over its entire life cycle, from production to use, maintenance and disposal (Swarr et al. 2011; Hunkeler et al. 2008). The life cycle costing implementation and results thus strongly depend on the chosen stakeholder. Indeed different data should be collected if we want to consider the costs paid and revenues obtained by the manufacturing company or when they are related to the consumer.

The LCC can also be used as a standalone method to assess economic and environmental performance of a product. In this case a monetization of the environmental externalities and economic costs is necessary. The monetization allows one to translate the relative environmental impacts (externalities) into costs, for example 
the carbon taxes. In general, the life cycle costing is more used in terms of cost engineering and it is performed by the industry with a different perspective than the LCA to calculate the business case of the project/product.

The social impacts are usually considered in the industry at corporate level; this means that social impacts are assessed per company and/or per each site of the company and usually the evaluation is extended only up to the first tier supplier.

This approach does not allow the integration of the results of the corporate social performance in the evaluation of a more sustainable component or material. To integrate the social considerations in the product development process, data on the social impact of a product life cycle should be collected.

According to the definition of UNEP/SETAC Life Cycle Initiative, the SLCA is defined as the assessment of social performance of a product along its life cycle and by considering at least five stakeholder groups: workers, customers, local community, society, and value chain actors not including consumers (UNEP/SETAC 2009). The SLCA is the youngest technique among the life cycle thinking approaches, and even if an UNEP/SETAC guideline and the relative Methodological Sheets (UNEP/ SETAC 2013; Benoît-Norris et al. 2011b) to support LCA users in the implementation have been published, the scientific community as well as the industry has not come to a complete agreement on several crucial points. Challenges of SLCA are: selection and definition of a valid and commonly accepted set of indicators, availability of inventory data at product level, definition of pathways from inventory to the impact assessment, and so on.

A big challenge is the necessity to collect primary data from company and local communities. The only example of database developed according to the UNEP/ SETAC guideline is the Social Hotspot Database (SHDB) (Benoit-Norris et al. 2011a). This database uses a Top-Down Input/Output approach to derive the social hotspot risk at country and sector level. The SHDB project offers an online database that allows users to browse data on social risks by sector, country, or risk theme. There are 227 countries and 57 economic sectors to choose from. The data comprehensively addresses social issues on human rights, working conditions, community impacts and governance issues, via a set of nearly 150 risk indicators grouped within 22 themes. Examples of sectors covered by the database are transport, transport equipment, motor vehicles and parts, and metal. It is clear that the SHDB can be used to make a screening on the potential risks of these sectors by country, but further efforts have to be paid for a primary data collection.

If on one hand, the scientific community is still debating the necessity and scientific validity of the social assessment at product level, on the other hand the media's, NGOs', and customers' concern about the consequences of buying a product that is produced under bad social conditions is increasing.

No specific initiative has been made at product level from the automotive sector. Most of the activities that have been developed are to improve the sustainability and social performance of the supply chain, by identifying social hotspots. An example of this initiative was the development of a common sustainability questionnaire among the OEMs of the automotive sector to screen the sustainability performance of the suppliers. 
The most recent industrial social assessment initiatives that have been developed at product level are: the Roundtable of Product Social Metrics, Social Metrics for chemical sector by WBCSD, and case studies conducted on the SLCA of electronics products by the Sustainability Consortium. There are no specific initiatives on the SLCA from the automotive sector.

BMW Group is one of the founding members of the Roundtable of Product Social Metrics. In 2013, for the first time, a group of companies decided to sit down together and to define, based on the literature, the ILO Conventions and their strategy in order to develop a common methodology to assess social performance of a product along its life cycle.

The project is now running the third phase and the main results of the previous phases are included in the Handbook of Product Social Impact Assessment (Fontes et al. 2014). Six case studies were realized, mainly among the Roundtable members, to implement and validate the methodology presented in the handbook. This initiative, that also involved BMW Group, shows that the SLCA is a feasible and practicable methodology. The main challenge in its implementation is the necessity to directly involve the entire supply chain to collect primary social inventory data. Because these data are very sensitive, a strong cooperation and linking interests between OEM (requesting the primary data) and each 1-tier supplier (data giver) are necessary.

This challenge also existed for the environmental LCA 20 or 30 years ago, when software and databases such as $\mathrm{GaBi}^{\circledR}$ (PE International 2010) and $\mathrm{SimaPro}^{\circledR}$ (PRé Consultants 2013) were not available and performing an LCA of a product cost significant effort in terms of time and money just to collect primary data.

\section{Results and Discussion}

The long walk to a more sustainable production and consumption is a trip that needs to be taken by the actors of different sectors in a participatory and harmonized manner. The automotive industry can play a strategic role in creating this partnership and cooperation and it will affect all sectors connected with the automotive one, such as metals or electronics. Many challenges still have to be faced in moving towards a comprehensive life cycle sustainability assessment of a vehicle and some of them are methodological. A relative harmonized approach is used to assess the environmental performance of a product along its life cycle according to ISO 14040/44. BMW uses the LCA not only for assessing its vehicles, but as a supporting tool to address choices and decisions along the entire development process, from product concept creation to the vehicle's start-of-production. Measurable targets for the full life cycle are identified and established in the earliest stages of the development process. These are monitored and documented during vehicle development and the results independently certified as requested by the ISO 14040 standard. Therefore the LCA is mainly used as an internal supporting decision-making tool towards a more sustainable production. 
The SLCA has taken the first step towards a more harmonized approach with the Handbook of Product Social Impact Assessment, even if the scientific community has not yet found a methodological solution for all implementation steps. Indeed, according to the LCA approach, more efforts have to be made to develop characterization factors which allow the translation of the inventory indicators (such as Living Wage and Working Hours) into the impact categories (Human Well-being, or Human Dignity).

Open Access This chapter is distributed under the terms of the Creative Commons Attribution Noncommercial License, which permits any noncommercial use, distribution, and reproduction in any medium, provided the original author(s) and source are credited.

\section{References}

Aluminium Stewardship Initiative (2014) http://aluminium-stewardship.org/. Accessed 12 Feb 2015

Benoît-Norris C, Aulisio D, Norris GA, Hallisey-Kepka C, Overakker S, Vickery Niederman G (2011a) A social hotspot database for acquiring greater visibility in product supply chains: overview and application to orange juice. In: Finkbeiner M (ed) Towards life cycle sustainability management. Springer, 53-62. doi:10.1007/978-94-007-1899-9_6

Benoit-Norris C, Vickery-Niederman G, Valdivia S, Franze J, Traverso M, Ciroth A, Mazijn B (2011b) Introducing the UNEP/SETAC methodological sheets for subcategories of social LCA. The International Journal of Life Cycle Assessment. Springer, Berlin/Heidelberg, pp 1-9, 31 May 2011. ISSN: 0948-3349

BMW Group (2010) BMW efficient dynamics. Joy powered by tomorrow's technologies - today as a standard. http://www.bmw.com/com/en/insights/technology/efficient_dynamics/phase_2/_ shared/catalogue/pdf/efficient_dynamics_catalogue.pdf. Accessed 22 Feb 2015

BMW Group (2013) Sustainable value report 2013. http://www.bmwgroup.com/com/en/responsibility/sustainability/sustainability-management/index.html. Accessed $22 \mathrm{Feb} 2015$

BMW Group (2014) Environmental certification BMW i3. http://www.bmwgroup.com/com/en/_ common/_pdf/Enviromental_Certification_i3.pdf. Accessed 22 Feb 2015

Finkbeiner M, Schau E, Lehmann A, Traverso MT (2010) Life cycle sustainability assessment. Sustainability 2(10):3309-3322. http://www.mdpi.com/2071-1050/2/10/3309/

Fontes J, Bolhuis A, Bogaers K, Saling P, van Gelder R, Traverso M, Das Gupta J, Bosch H, Morris D, Woodyard D, Bell L, van der Merwe R, Laubscher M, Jacobs M, Challis D, Alvarado C, Duclaux C, Slaoui Y, Culley H, Zink S (2014) Handbook of product social impact assessment Version 2.0 PRé sustainability

Hunkeler D, Lichtenvort K, Rebitzer G (eds) (2008) Environmental life cycle costing. SETAC, Pensacola, FL (US) in collaboration with CRC Press, Boca Raton

IPCC (2001) Climate change 2000, impacts, adaptation and vulnerability, contribution of working group II to the third assessment report of the intergovernmental panel on climate change. Cambridge University Press, Cambridge

ISO (2006a) ISO 14040 - Environmental management - life cycle assessment - principles and framework. Geneva

ISO (2006b) ISO 14044 - Environmental management - life cycle assessment - requirements and guidelines. Geneva

Klöpffer W (2008) Life cycle sustainability assessment of products. Int J Life Cycle Assess 13(2):89-95 
PE International (2010) Gabi 4.3 LCA software. Leinfelden-Echterdingen. www.gabi-software. com/uk-ireland/index/

PRé Consultants (2013) Introduction to LCA with SimaPro 8. http://www.pre-sustainability.com/ download/SimaPro8IntroductionToLCA.pdf. Accessed 22 Feb 2015

Schmidt WP (2003) Life cycle costing as part of design for environment environmental business cases. Int J Life Cycle Assess 8(3):167-174. doi:10.1007/BF02978464

Swarr T, Hunkeler D, Klöpffer W, Pesonen H-L, Ciroth A, Brent AC, Pagan R (2011) Environmental life cycle costing: a code of practice. SETAC Press, Pensacola

UN (2012) United Nations secretary-general's high-level panel on global sustainability. Resilient people, resilient planet: a future worth choosing. United Nations, New York

UNEP/SETAC (2009) Guidelines for social life cycle assessment of products. $103 \mathrm{p}$

UNEP/SETAC (2012) Towards life cycle sustainability products. Edition UNEP/SETAC LCI

UNEP/SETAC (2013) The methodological sheets for social life cycle assessment - a practical support to implement SLCA of Product. http://www.lifecycleinitiative.org/wp-content/ uploads/2013/11/S-LCA_methodological_sheets_11.11.13.pdf. Accessed 22 Feb 2015

WCED (1987) Our common future. Oxford University Press, New York 